\title{
Taking the Dimers Out of Diazaheptacenes
}

\section{Key words}

azaaromatics

palladium

aromatic chemistry<smiles>CCCCC#Cc1c2ccccc2c(C#CC(C)C)c2cc(Br)c(Br)cc12</smiles><smiles>CCCCC#Cc1c2ccccc2c(C#C[GeH2]C(C)(C)C)c2cc(N)c(N)cc12</smiles>

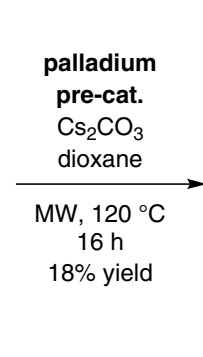<smiles>CCCCC#Cc1c2ccccc2c(C#C[AsH2]C(C)(C)C)c2cc(C)ccc12</smiles><smiles>CCCCC#Cc1c2ccccc2c(C#C[AsH2]C(C)(C)C)c2cc(N)c(N)cc12</smiles>

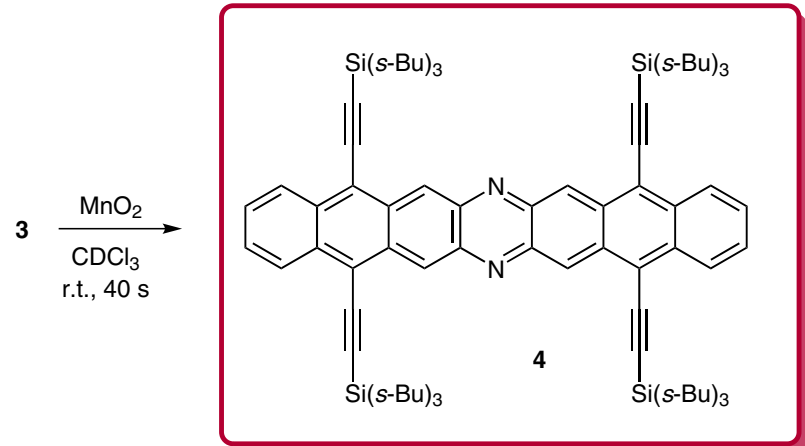<smiles>CCCOc1cccc(OP(=O)(Cl)[P-]2(Cl)NCCc3ccccc32)c1-c1ccccc1</smiles>

Significance: The authors have successfully designed, synthesized, and isolated the first persistent azaheptacene. The diazaheptacene in this work required four $\mathrm{Si}(\mathrm{s}-\mathrm{Bu})_{3}$-ethynyl groups to effectively prevent dimerization upon oxidizing to the final product 4
Comment: The key synthetic step was the fast oxidation using manganese oxide to convert 3 into 4, which was carried out for no longer than forty seconds. The product $\mathbf{4}$ was stable for approximately one hour, after which dimerization products were detected. Alternative trialkylsilyl-ethynyl groups, such as the TIPS-ethynyl group, proved ineffective at impeding dimerization. 


\section{Category}

Synthesis of

Materials and

Unnatural Products

\section{Key words}

triazoles

regioselectivity

tetrazoles

photochemistry
S. STEWART, R. HARRIS,* C. JAMIESON* (GLAXOSMITHKLINE MEDICINES RESEARCH CENTRE, STEVENAGE AND UNIVERSITY OF STRATHCLYDE, GLASGOW, UK)

Regiospecific Synthesis of N2-Aryl 1,2,3-Triazoles from 2,5-Disubstituted Tetrazoles via Photochemically Generated Nitrile Imine Intermediates

Synlett 2014, 25, 2480-2484.

\section{Triazole Your Tetrazoles}

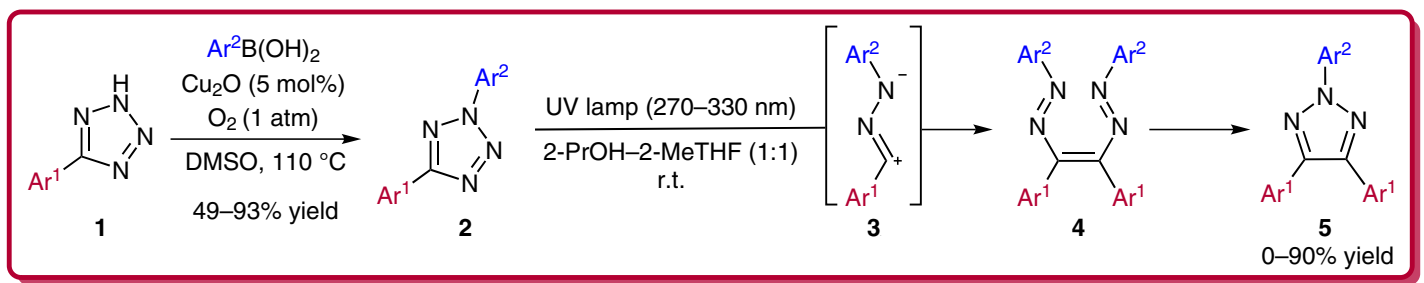

Selected examples of $\mathbf{5}$ :

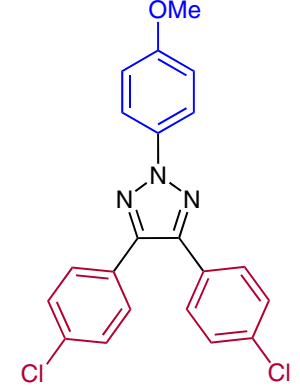

$67 \%$ yield $16 \mathrm{~h}$<smiles>c1ccc(-c2nc(-c3ccccc3)n(-c3ccccc3)n2)cc1</smiles>

$19 \%$ yield $24 \mathrm{~h}$

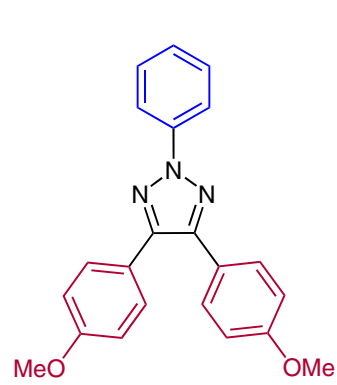

$38 \%$ yield $30 \mathrm{~h}$<smiles>O=[N+]([O-])c1ccc(-n2nc(-c3ccccc3)c(-c3ccccc3)n2)cc1</smiles>

$0 \%$ yield $>100 \mathrm{~h}$<smiles>COc1ccc(-c2nn(-c3ccc(OC)cc3)nc2-c2ccc(OC)cc2)cc1</smiles><smiles>CCOC(=O)c1ccc(-n2nc(-c3ccccc3)c(-c3ccccc3)n2)cc1</smiles>

$90 \%$ yield

$7 \mathrm{~h}$

$14 \%$ yield $23 \mathrm{~h}$<smiles>N#Cc1cccc(-n2nc(-c3ccccc3)c(-c3ccccc3)n2)c1</smiles>

$0 \%$ yield $24 \mathrm{~h}$
Significance: Stewart, Harris, and Jamieson developed a one-step reaction to photochemically synthesize N2-aryl 1,2,3-triazoles 5 from 2,5-diaryl tetrazoles $\mathbf{2}$. This method bypasses issues of regioselectivity by first preparing the appropriate $\mathrm{N}$-arylated tetrazole, which under UV irradiation forms a nitrile imine intermediate $\mathbf{3}$ that dimerizes and rearranges to produce the appropriate N2aryl 1,2,3-triazole.

SYNFACTS Contributors: Timothy M. Swager, Sarah P. Luppino Synfacts 2015, 11(1), $0030 \quad$ Published online: 15.12.2014 DOI: 10.1055/s-0034-1379669; Reg-No.: S12814SF
Comment: Electron-donating substituents and dilute conditions led to improved yields of the triazoles, while electron-deficient $N$-aryl substituents led to poor or zero conversion. Previous studies of similar starting materials identified tetrazine as the final product, but the authors indicate that the only other compound isolated in their study was the Wanzlick dimer $\mathbf{4}$, which can be converted into the final triazole with additional UV irradiation. 


\section{Twin Helicenes Twist Benzene}<smiles>Brc1c(Br)c(Br)c(Br)c(Br)c1Br</smiles>

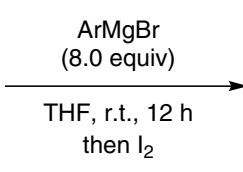<smiles>Brc1c(Br)c(Br)c(Br)c(Br)c1Br</smiles>

1. $t$-BuLi (4.5 equiv) 2. $\mathrm{CIP}\left(\mathrm{NEt}_{2}\right)_{2}$ (2.8 equiv)

1

$222 \%$ yield

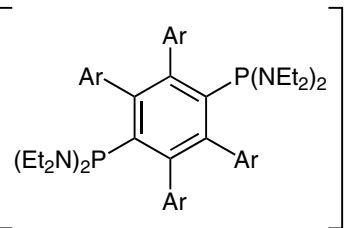

3
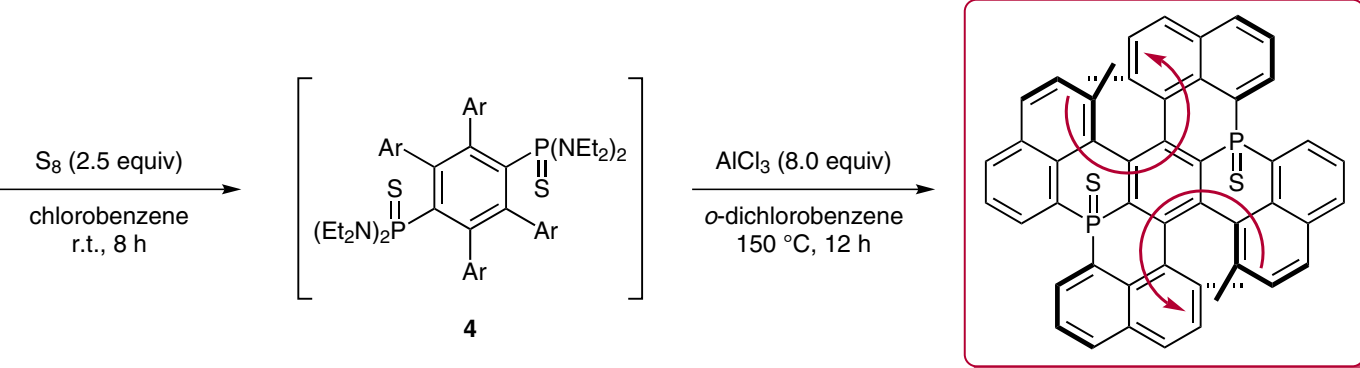

5 10\% yield from 2

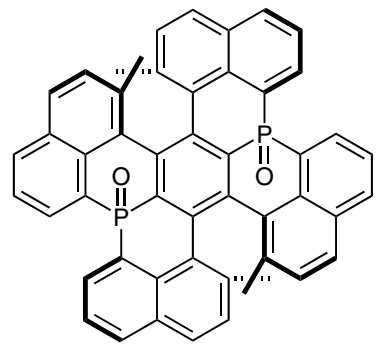

$675 \%$ yield

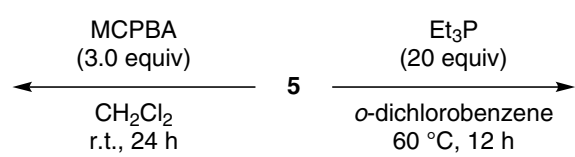

$60{ }^{\circ} \mathrm{C}, 12 \mathrm{~h}$

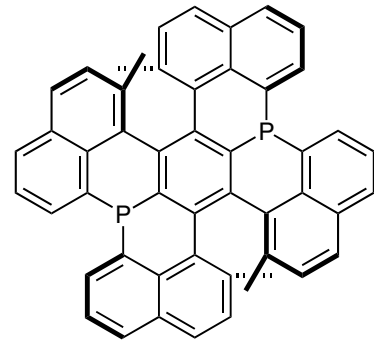

$789 \%$ yield
Significance: The authors report a new approach to construct distorted benzene rings by constraining a benzene ring between two opposing [5]helicenes. Double helicene $\mathbf{5}$ was synthesized via a tandem intramolecular phospha-Friedel-Crafts reaction. By X-ray crystallography, the central benzene ring of $\mathbf{5}$ was found to possess a bending angle of $23^{\circ}$, and the sulfur atoms were found to be in a cis arrangement.
Comment: Distorted double helicene $\mathbf{5}$ can be desulfurized with triethylphosphine to yield bis(phosphine) 7 , which could find potential use as a $\mathrm{C}_{2}$ symmetric ligand for bimetallic complexes, following separation of enantiomers. 


\section{Category}

Synthesis of

Materials and

Unnatural Products

\section{Key words}

divergent synthesis

biselenophenes
Y.-C. PAO, Y.-L. CHEN, Y.-T. CHEN, S.-W. CHENG, Y.-Y. LAI, W.-C. HUANG, Y.-J. CHENG* (NATIONAL CHIAO TUNG UNIVERSITY, HSIN-CHU, TAIWAN)

Synthesis and Molecular Properties of Tricyclic Biselenophene-Based Derivatives with Nitrogen, Silicon, Germanium, Vinylidene, and Ethylene Bridges

Org. Lett. 2014, 16, 5724-5727.

\section{Divergent Synthesis of Tricyclic Biselenophene-Based Derivatives}

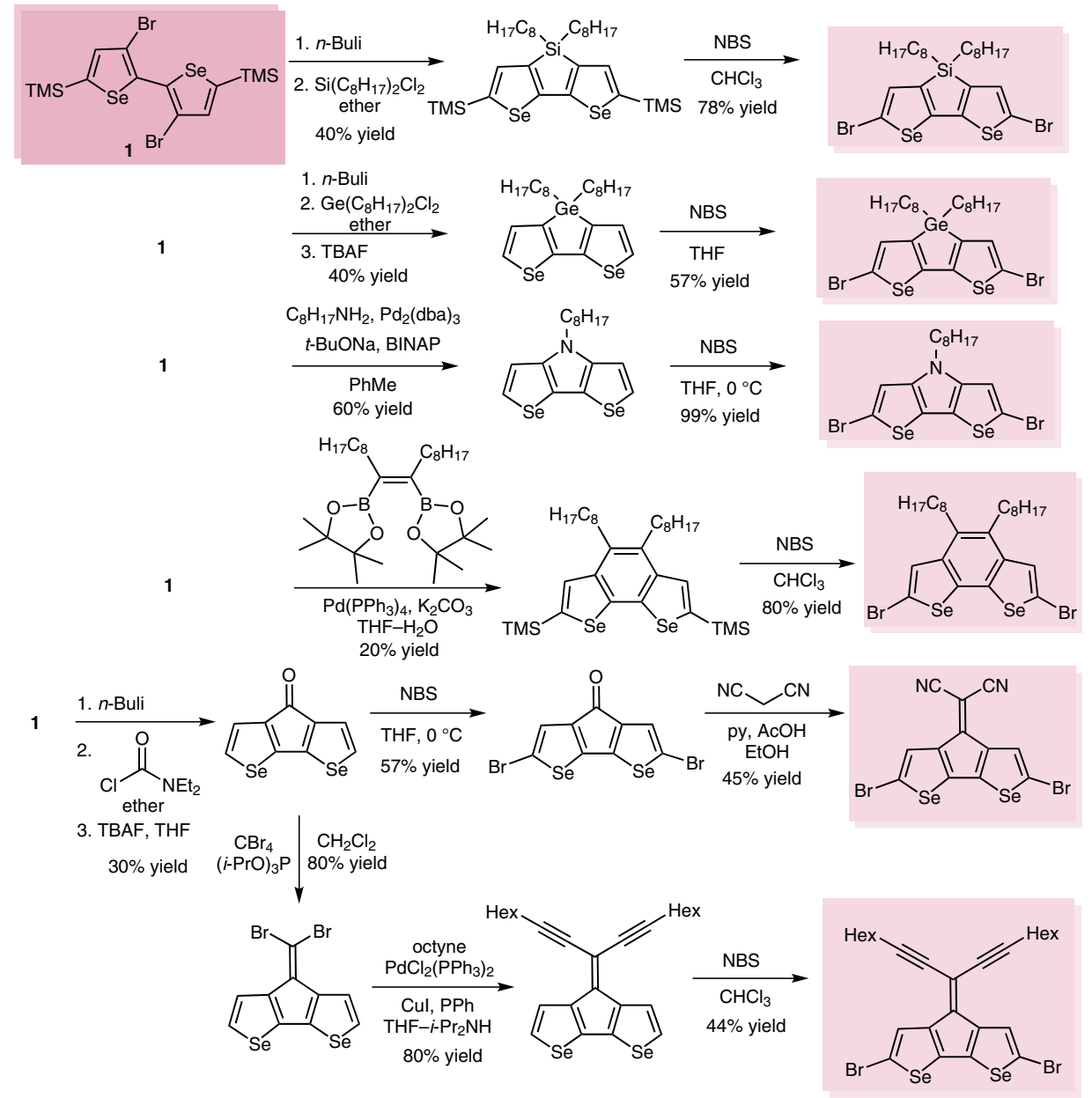

Significance: While tricyclic bithiophene-based materials have been extensively studied as an important class of organic semiconductors, the corresponding biselenophene-based analogues have not been reported. Cheng and co-workers demonstrate for the first time that biselenophene $\mathbf{1}$ can be utilized as starting material for the synthesis of a new class of both $\mathrm{sp}^{3}$-bridged and $\mathrm{sp}^{2}$ bridged tricyclic biselenophene-based materials.
Comment: The six brominated molecules highlighted above can be used as monomers to create a new class of $\mathrm{p}$ - or $\mathrm{n}$-type polymers for exploring biselenophene-based materials in various optoelectronic applications, such as organic field-effect transistors and polymer solar cells. 


\section{Having the Gall to Synthesize Conjugated Polymers Containing Gallium Atoms}

\section{Key words}

gallium

conjugated polymers

cross-coupling

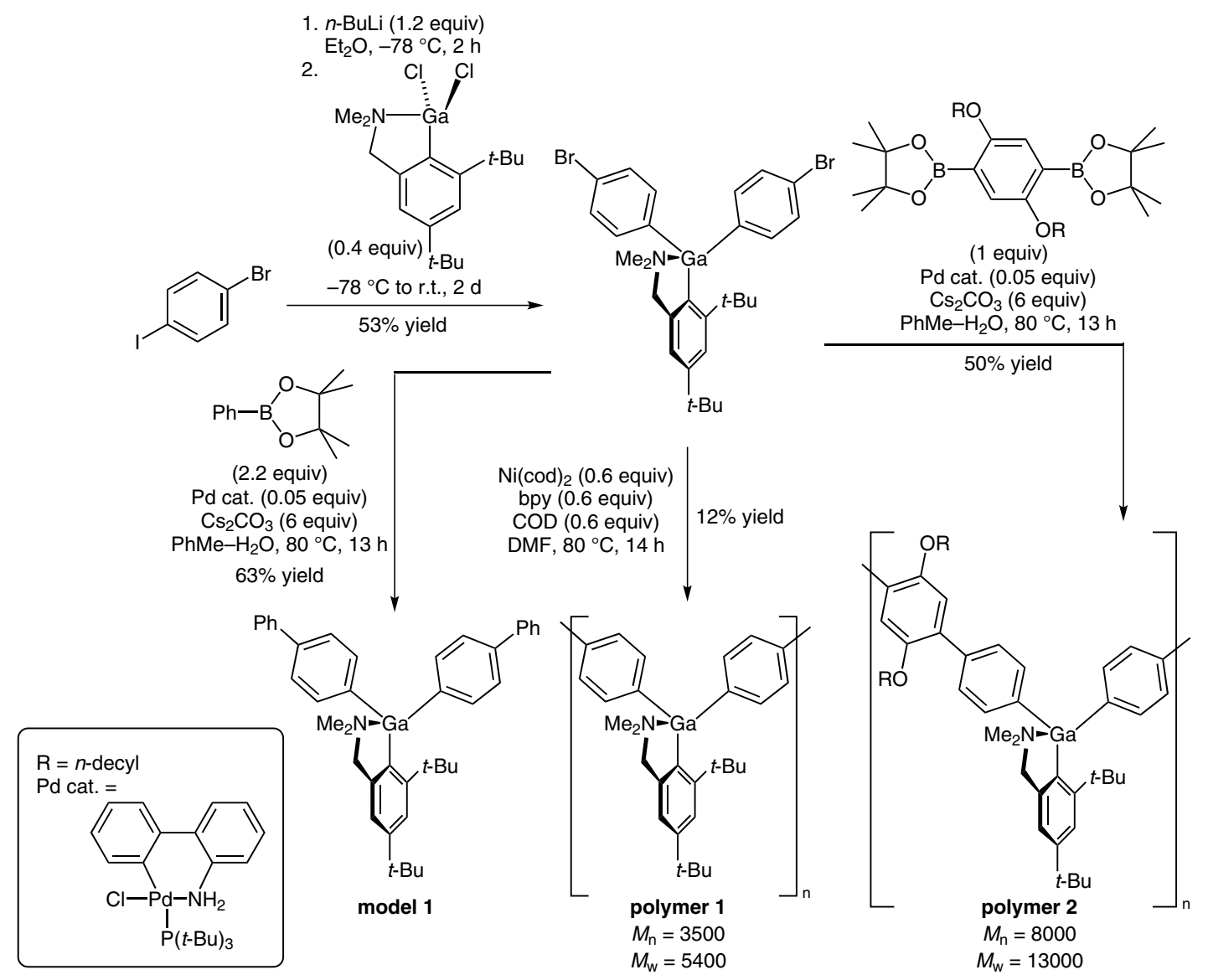

Significance: The effect of gallium atoms in conjugated polymers is relatively unexplored, in part due to the air and moisture sensitivity of three-coordinate gallium centers. Tanaka, Chujo, and coworkers utilize a four-coordinate gallium monomer in which the gallium is stabilized by amine chelation and bears two 4-bromophenyl moieties. With Suzuki-Miyaura or Yamamoto coupling, a variety of air-stable $\pi$-systems containing gallium atoms are obtained. UV/Vis and DFT studies show that $\pi$-conjugation extends through the gallium atoms.
Comment: This study shows that gallium atoms can be incorporated into air-stable conjugated polymers. While typical aryl-aryl coupling conditions are employed in this study, relatively poor polymer yields and lengths are obtained. Future optimization of polymerization conditions could facilitate the development of gallium-containing polymers.

SYNFACTS Contributors: Timothy M. Swager, Sibo Lin 


\section{Gategory}

Synthesis of

Materials and

Unnatural Products

\section{Key words}

fluorophores

Stille coupling

dyes
H. WANG, F. R. FRONCZEK, M. G. H. VinCENTE, K. M. SMITH* (LOUISiAnA STATE UNIVERSITY, BATON ROUGE, USA)

Functionalization of 3,5,8-Trichlorinated BODIPY Dyes

J. Org. Chem. 2014, 79, 10342-10352.

\section{Phosgene as Key Reagent for Trifunctionalization of BODIPY Dyes}<smiles>Cc1[nH]c(C(=O)O)c(C)c1[18O]</smiles>

1. $\mathrm{Br}_{2}$ (1 equiv)

$\mathrm{Et}_{2} \mathrm{O}$, r.t., overnight

2. $\mathrm{MeOH}$, reflux, overnight

$70 \%$ yield

$\mathrm{BnO}_{2} \mathrm{C}$

$\mathrm{R}^{1}=\left(\mathrm{CH}_{2}\right)_{2} \mathrm{CO}_{2} \mathrm{Me}$<smiles>Cc1c(Cl)c2n(c1Cl)B(F)P(F)n1c(I)c(I)c(Cl)c1-2</smiles>

$\mathrm{Pd}\left(\mathrm{PPh}_{3}\right)_{4}(0.05$ equiv) $\mathrm{PhMe}$, reflux, $5 \mathrm{~h}$

1. DIPEA (7 equiv) $\mathrm{CHCl}_{3}$, r.t., $30 \mathrm{~min}$

2. $\mathrm{BF}_{3} \cdot \mathrm{OEt}_{2}$ (10 equiv) r.t., $24 \mathrm{~h}$

$55 \%$ yield<smiles>Cc1ccccc1Cc1[nH]c(C(=O)OCc2ccccc2)c(C)c1C(=O)OCc1ccccc1</smiles>

1. $\mathrm{Pb}(\mathrm{OAc})_{4}$ (2.2 equiv) $\mathrm{AcOH}$, r.t., $4 \mathrm{~d}$

2. $\mathrm{PbO}_{2}$ (2.9 equiv), $2 \mathrm{~d}$

$60 \%$ yield

1. $\mathrm{Pd} / \mathrm{C}, \mathrm{H}_{2}$ THF, r.t., overnight

2. $I_{2}$ ( 1.5 equiv)

$\mathrm{NaHCO}_{3}$ (5.1 equiv) $\mathrm{H}_{2} \mathrm{O}-\mathrm{MeOH}$, r.t., $2 \mathrm{~h}$,
Significance: The functionalization of BODIPY fluorescent dyes allows the tuning of their photophysical, hydrophobic, and charge-transfer properties. Smith and co-workers utilize phosgene to access a 3,5,8-trichlorinated BODIPY. Exploiting the higher reactivity of the vinylic chloride in Stille couplings, regioselectively functionalized BODIPY dyes are synthesized.
Comment: Starting from a trichlorinated BODIPY and performing mixed Stille couplings with only four different organotin reagents, 14 new BODIPY dyes are reported in this paper. Photophysical properties are tunable via substitution at the 3-, 5-, and 8-positions. A plethora of regioselectively functionalized BODIPY dyes should be accessible through this strategy.

SYNFACTS Contributors: Timothy M. Swager, Sibo Lin

Synfacts 2015, 11(1), 0034 Published online: 15.12.2014 Dol: 10.1055/s-0034-1379663; Reg-No.: S12214SF 


\section{PB\&J: Phosphorus and Boron at the Junction of Two $\pi$-Systems}

\section{Category}

Synthesis of Materials and Unnatural Products

\section{Key words}

electrocyclization

ring closure

ring opening

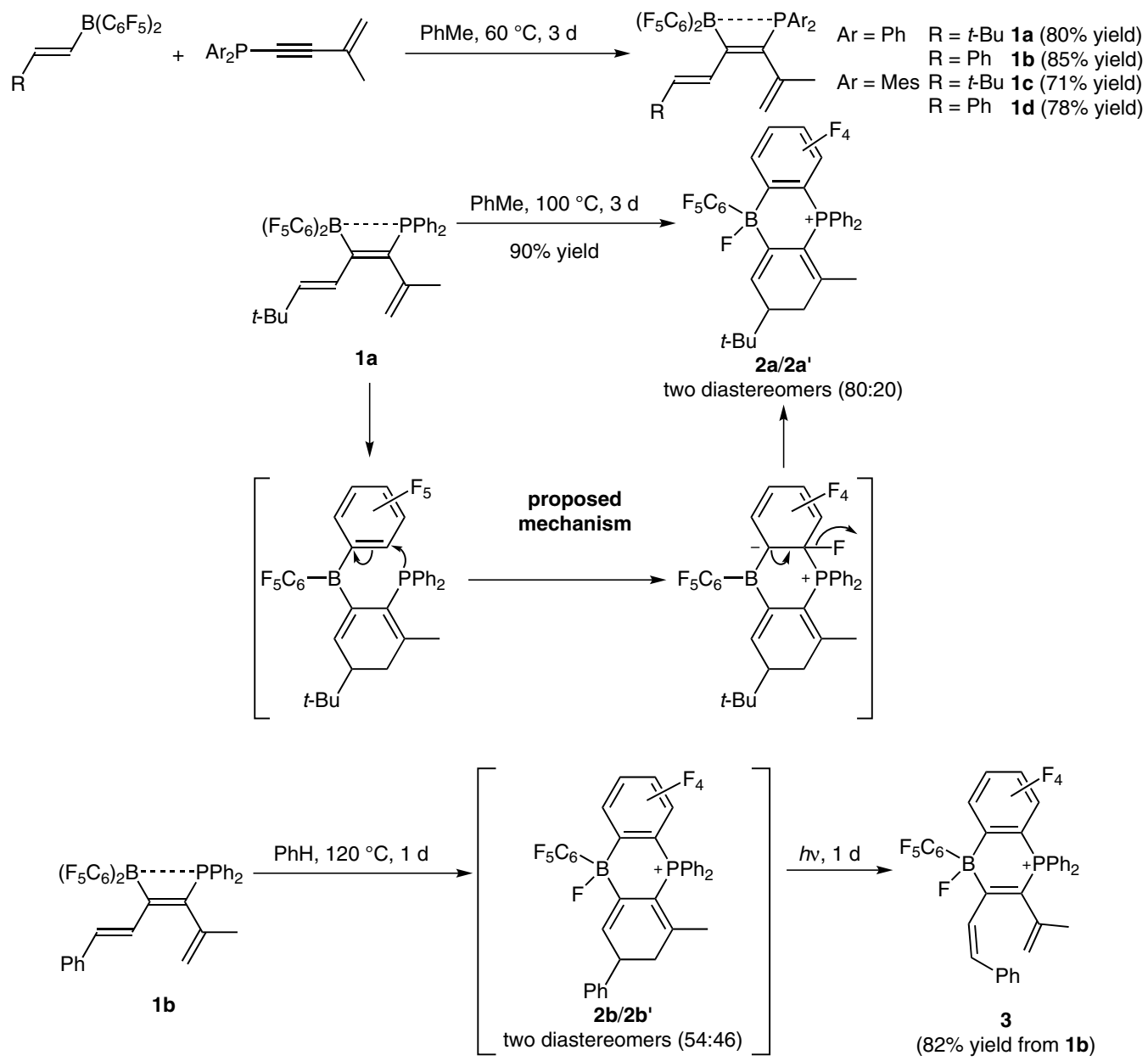

Significance: The 1,1-alkenylboration of alkynes is an unique route to large conjugated $\pi$-systems. Erker and co-workers demonstrate that the 1,1alkenylboration of diarylphosphino-enynes proceeds similarly to give hexatrienes 1. Upon thermolysis, two concurrent transformations occur: $6 \pi$-electrocyclic ring closure of the hexatriene moiety and nucleophilic aromatic substitution $\left(S_{N} A r\right)$ of a pentafluorophenyl group by the phosphine nucleophile to yield heterotricyclic products 2 .
Comment: These reactions are a convenient synthetic route to new molecules containing vicinal $\mathrm{P} / \mathrm{B}$ Lewis pairs. Thermolysis products are only reported for $\mathbf{1 a}$ and $\mathbf{1 b}$. Would the thermolysis of $\mathbf{1 c}$ and $\mathbf{1 d}$, which contain bulky (Mes) ${ }_{2} \mathrm{P}$ nucleophiles, result in electrocyclic ring closure without concurrent $S_{N} A r ?$

SYNFACTS Contributors: Timothy M. Swager, Sibo Lin 


\section{Gategory}

Synthesis of

Materials and

Unnatural Products

\section{Key words}

graphene nanoribbons

cyclodehydrogenation

\section{Diels-Alder} reaction

\section{near-infrared} absorption

X. FENG, ${ }^{*}$ K. MÜLLEN* ET AL. (MAX PLANCK INSTITUTE FOR POLYMER RESEARCH, MAINZ AND FREE UNIVERSITY BERLIN, GERMANY; UNIVERSITY OF LEUVEN, BELGIUM; FOM INSTITUTE AMOLF, AMSTERDAM, THE NETHERLANDS; AARHUS UNIVERSITY, DENMARK; MANCHESTER UNIVERSITY, UK)

Bottom-Up Synthesis of Liquid-Phase-Processable Graphene Nanoribbons with Near-Infrared Absorption ACS Nano 2014, 8, 11622-11630.

\section{A Diels-Alder Approach to Graphene Nanoribbon Precursors}

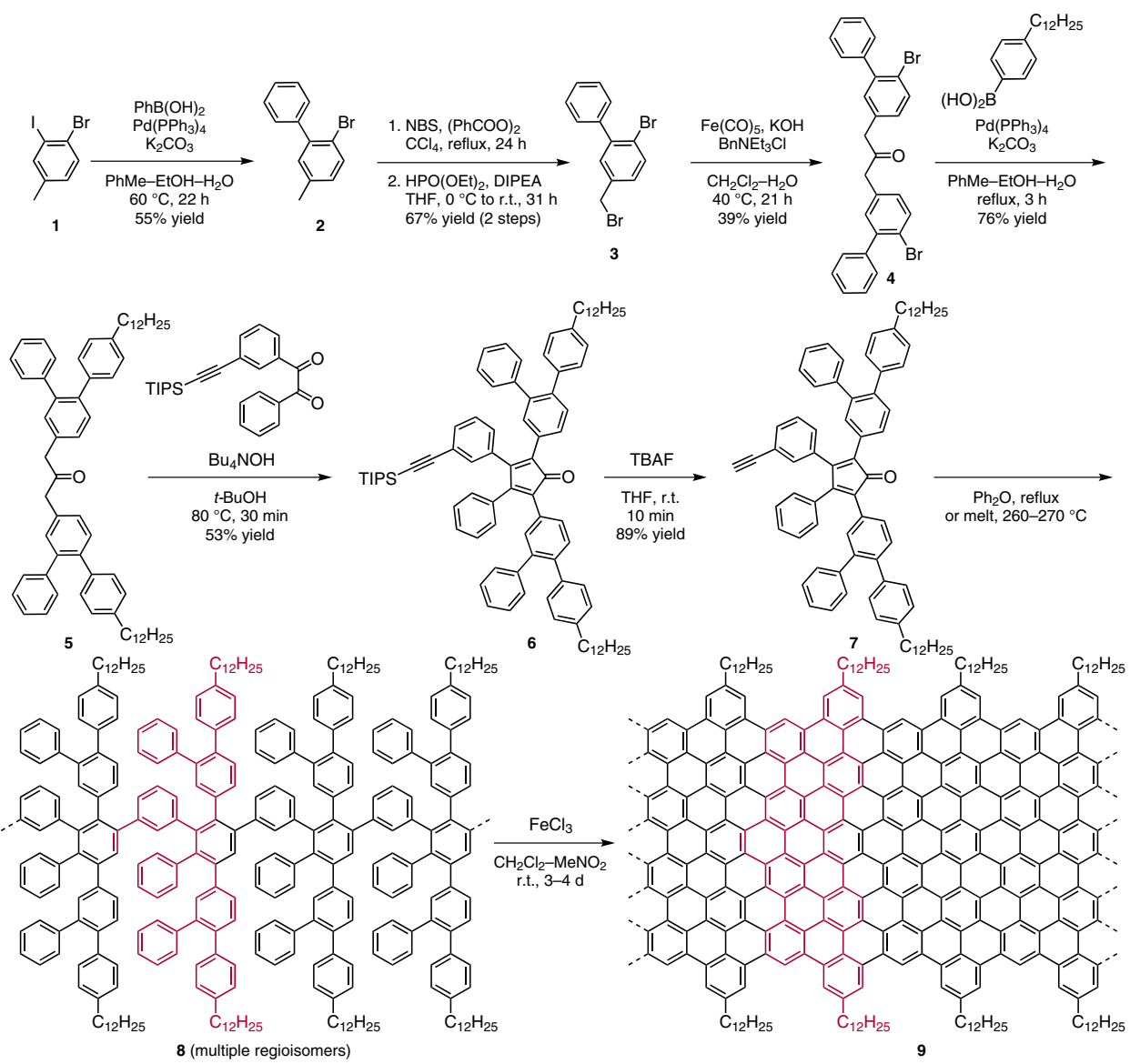

Significance: Bottom-up approaches to graphene nanoribbons (GNRs) have been limited by the short length of nanoribbons produced $(<50$ $\mathrm{nm}$ ) or the requirement for metal surfaces. The authors report a bottom-up approach to the synthesis of longer (>100 nm), structurally defined GNRs using an $A B$-type Diels-Alder polymerization to form nanoribbon precursors 8 that can be planarized to GNRs 9 by oxidative cyclodehydrogenation with $\mathrm{FeCl}_{3}$

SYNFACTS Contributors: Timothy M. Swager, Kathleen R. White Synfacts 2015, 11(1), 0036 Published online: 15.12.2014 DOI: 10.1055/s-0034-1379666; Reg-No.: S12514SF 


\section{Not-So-Triyne Route to Heteroarylene and Arylene Macrocycles}

\section{Key words}

electronic materials

[2+2+2]

cycloaddition

rhodium catalysis

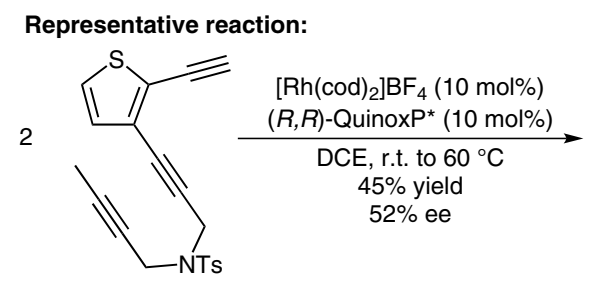

Selected compounds:
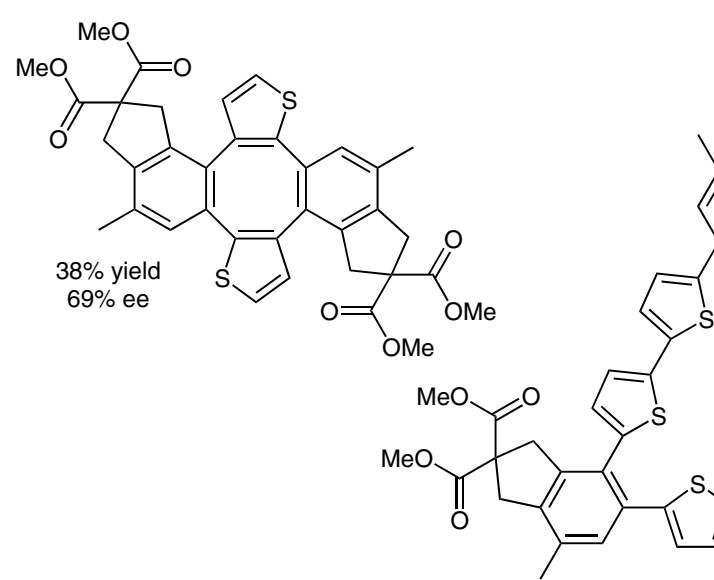

$50 \%$ yield

Significance: This is the first reported synthesis of macrocyclic $\pi$-conjugated structures featuring both benzene and heterocycle units. Isolated yields up to $~ 85 \%$ and stereochemical purity up to $\sim 95 \%$ ee are reported, though it is difficult to achieve both simultaneously. Bis- and tri-thiophene substrates produce trimers. While absorbance maxima were red-shifted with increasing thiophene rings, fluorescence maxima were not, indicating poor conjugation through the benzene ring vertices. However, this resulted in large Stokes shifts (90-120 nm) for these structures.
Comment: Ligand selection was found to be crucial for stereoselectivity, with QuinoxP* overall performing well. In trimer-forming systems, preference for dimer or trimer can also be tuned by ligand choice. The proposed mechanism is two rounds of metallacyclopentadiene formation followed by $[2+2+2]$ cyclization. Stereochemistry is determined by the second [2+2+2] cyclization step. While thiophene-based systems performed well, attempts to use furans resulted in poor yields and stereoselectivity. 


\section{Category}

Synthesis of

Materials and

Unnatural Products

\section{Key words}

\section{furans}

oligomers

conducting

polymers

electropolymerization

D. SHEBERLA, * S. PATRA, Y. H. WIJSBOOM, S. SHARMA, Y. SHEYNIN, A.-E. HAJ-YAHIA, A. H. BARAK, O. GIDRON, M. BENDIKOV (WEIZMANN INSTITUTE OF SCIENCE, REHOVOT, ISRAEL)

Conducting Polyfurans by Electropolymerization of Oligofurans

Chem. Sci. 2015, 6, 360-371.

\section{Electropolymerization Furnishes Conducting Polyfuran Films}

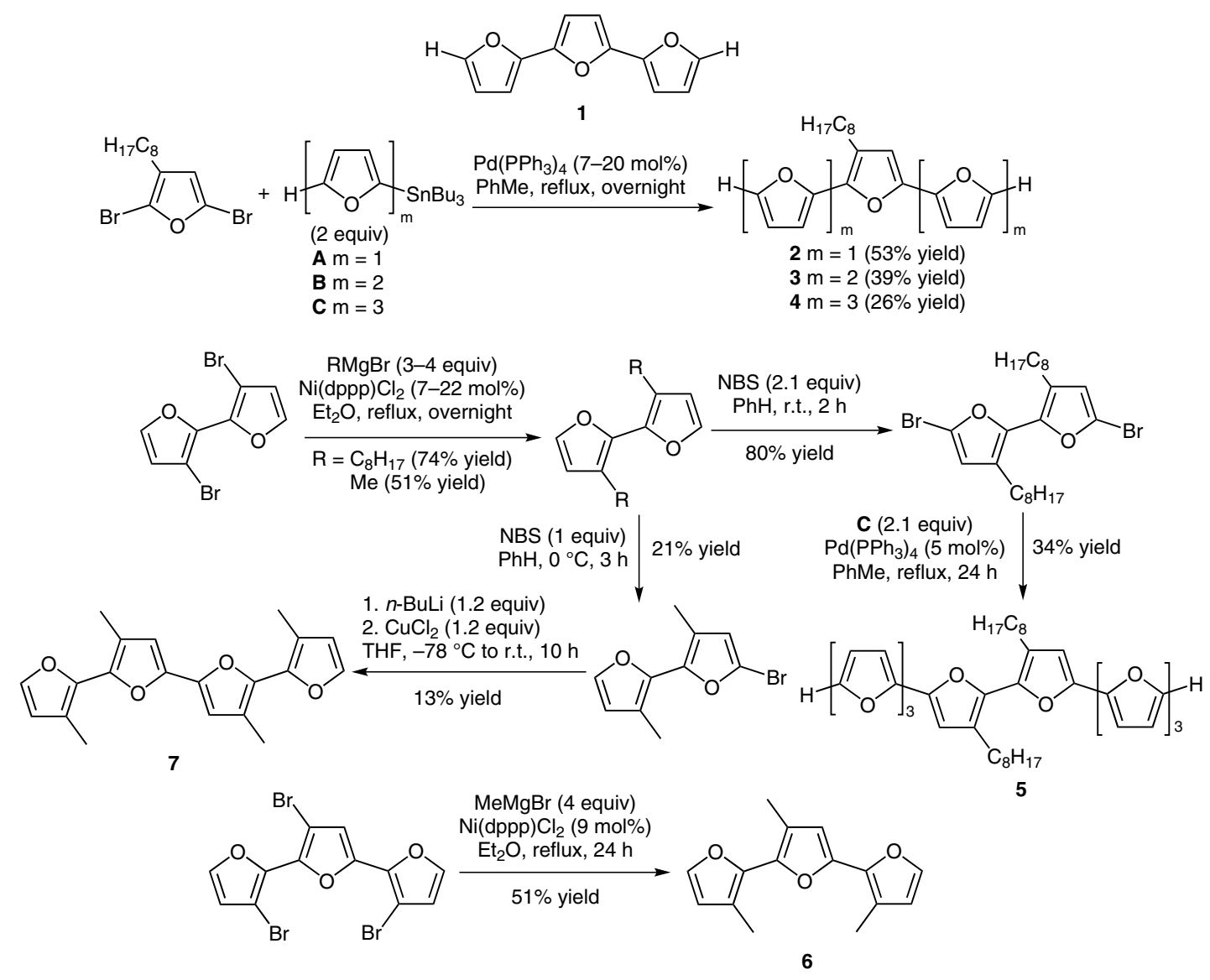

Significance: Polyfurans have received less research attention than their pyrrole and thiophene analogues. This is due in part to the high oxidation potential of furan. Harsh electropolymerization conditions result in defect-rich, non-conducting polyfuran. To lower the potential required to form polyfuran, Sheberla and co-workers synthesize oligofurans 1-7. Potentiostatic polymerization for all of these monomers occurs at $0.75 \mathrm{~V}$ (vs. Ag/ $\mathrm{AgCl})$. The resulting polyfurans are found to have conductivities comparable with electropolymerized polythiophenes.

SYNFACTS Contributors: Timothy M. Swager, Sibo Lin Synfacts 2015, 11(1), 0038 Published online: 15.12.2014 DoI: 10.1055/s-0034-1379665; Reg-No.: S12414SF
Comment: Electropolymerization of furan occurs at potentials in excess of $1.8 \mathrm{~V}$ (vs. $\mathrm{Ag} / \mathrm{AgCl})$. The onset oxidation potentials for $\mathbf{1 - 7}$ are under $0.7 \mathrm{~V}$, and follow expected trends based on conjugation length and degree of alkyl substitution. The highquality polyfurans also undergo oxidative doping at lower potentials than analogous poly(terthiophene)s, resulting in increased stability under the operating conditions. This study may establish polyfuran as a competitor to other conducting polymers. 


\section{A High Cyano Content Indacene as a Stable Organic Electron Acceptor}

\section{Key words}

electron acceptor

indacenes

nitriles
Significance: The authors used rational design to target the reported structure, compound $\mathbf{1}$. The indacene framework was stabilized by the high degree of cyano functionalization without compromising ease of reduction, which has been an issue with indacenes stabilized by benzannulation. The high cyano content also lowered the LUMO to $-5.8 \mathrm{eV}$. Cyclic voltammetry shows four reversible single electron transfers, and UV/Vis shows a band gap of $\sim 1.9 \mathrm{eV}$.
Comment: The synthesis began from a previously reported compound (C. Adams et al. Inorg. Chim. Acta 2011, 366, 44), produced $330 \mathrm{mg}$ of pure $\mathbf{3 a}$, and should be scalable. Compound $\mathbf{3 a}$ was found to be generally stable both as a solid and in solution, possibly due to the low-lying LUMO. 


\section{Gategory}

Synthesis of

Materials and

Unnatural Products

\section{Key words}

bromination

triptycene

tris(thiadiazoles)
B. KOHL, L. C. OVER, T. LOHR, M. VASYLYEVA, F. ROMINGER, M. MASTALERZ* (RUPRECHT-KARLS-UNIVERSITÄT HEIDELBERG, GERMANY)

Selective Even-Numbered Bromination of Triptycene Tris(thiadiazoles)

Org. Lett. 2014, 16, 5596-5599.

\section{An Unusual Regioselective Di-, Tetra-, and Hexa-Bromination}
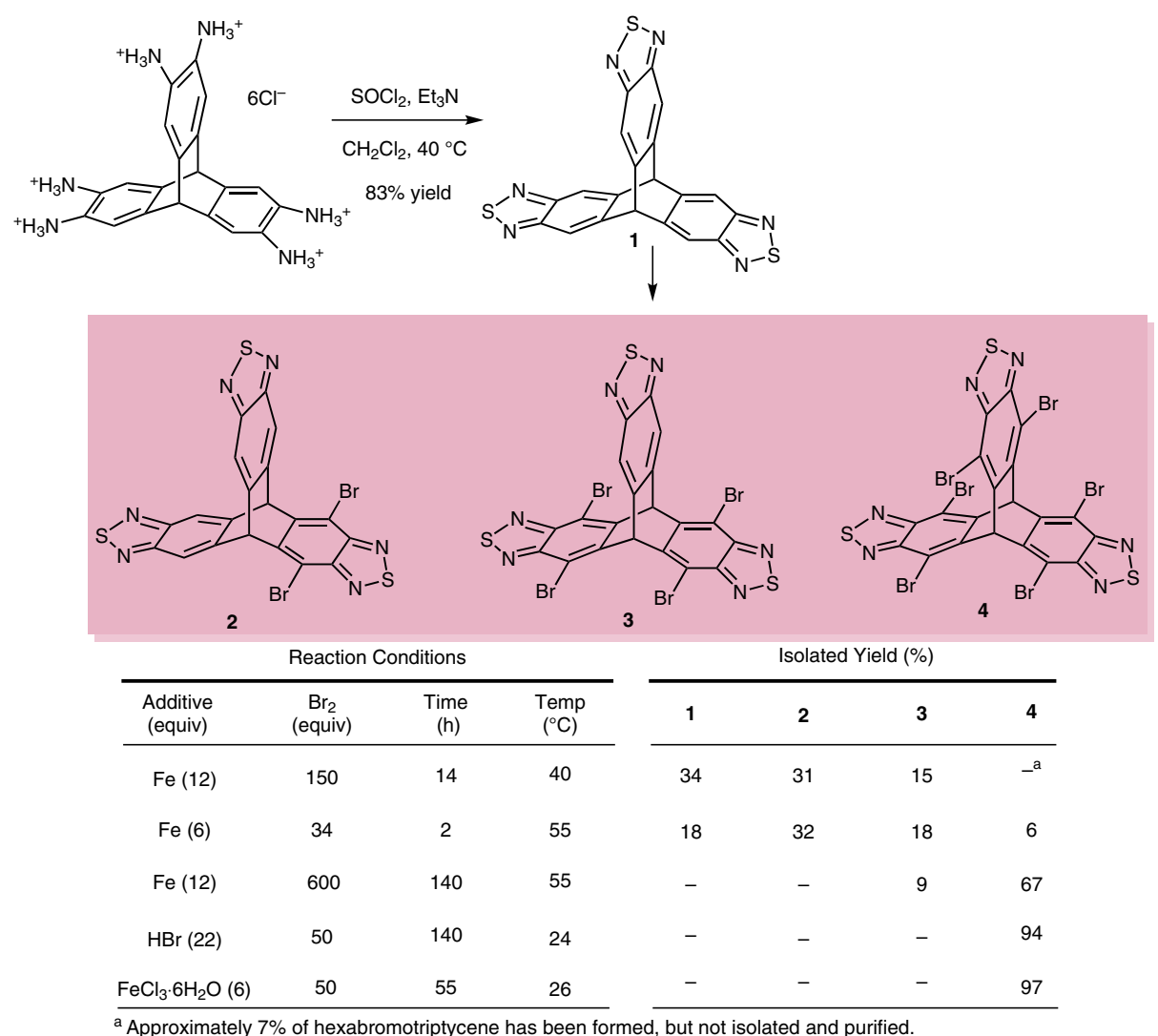

Significance: Mastalerz and co-workers report an unusual even-numbered bromination of triptycene tris(thiadiazoles), yielding regioselectively dibromo-, tetrabromo-, and hexabromotriptycenes with two bromines each on the same phenyl ring. These brominated compounds will be useful in the synthesis of $\pi$-conjugated polymers of intrinsic microporosity and small electron acceptors.
Comment: Given that the $\mathrm{C}-\mathrm{C}$ bond lengths of the phenyl rings are alternating, and hence the phenyl rings exhibit more olefinic than aromatic character from X-ray single crystal structure of $\mathbf{1}$, the mechanism for this unusual even-numbered bromination is proposed to involve 1,4-addition of $\mathrm{Br}_{2}$, followed by subsequent re-aromatization of the phenyl ring by oxidation by $\mathrm{Br}_{2}$ or $\mathrm{FeBr}_{3}$. It is also proposed that this 1,4-addition-oxidation sequence is favored over electrophilic aromatic substitution. Furthermore, to demonstrate the utility of these monomers in the synthesis of conjugated polymers, dibromotriptycene 2 has been shown to undergo facile Suzuki-Miyaura cross-coupling.

SYNFACTS Contributors: Timothy M. Swager, Wen Jie Ong Synfacts 2015, 11(1), 0040 Published online: 15.12.2014 Dol: 10.1055/s-0034-1379672; Reg-No.: S13114SF 